\title{
Analysis of natural vibration characteristics of pre-stressed apace truss
}

\author{
Zhicheng Lin $^{\mathrm{a}}$, Chengwei Huang ${ }^{\mathrm{b}}$, Fei He ${ }^{\mathrm{c}}$, Qiongxian Gao ${ }^{\mathrm{d}}$ \\ Kunming University of Science and Technology, Yunnan, Kunming, China \\ a376583421@qq.com, b994048762@qq.com, \\ c1353428988@qq.com, d1808344101@qq.com
}

Keywords: pre-stressed apace truss; block Lanczos; natural vibration characteristics factors.

\begin{abstract}
Vibration characteristics of the seismic analysis of structures are a prerequisite. The natural vibration characteristics is the precondition of aseismic analysis .This paper uses the block Lanczos method to calculate the evacuation of prestressed truss natural frequencies and formation, prestressed value analysis, the impact of grid height, mesh size and prestressed cable strut height of the vibration characteristics of the structure, and summed up the relevant laws for structural design.
\end{abstract}

\section{Introduction}

Along with social economy development, the construction sector in the emergence of many new forms of spatial structure, spatial structure typically includes a shell structure, grid structure , lattice shell structure, cable structure, membrane structure, and by the two or more hybrid structures. Among them, the development on the fast, the most widely used is the grid mesh shell structure[1].

Vibration characteristics of a dynamic analysis of the basic dynamic characteristics. Features include natural vibration frequencies and mode shapes structure, the natural frequencies can be learned from the case of structural rigidity, has a decisive effect on the dynamic response of the structure [2] . By calculating natural frequency calculation structure can reduce harm resonance structures under dynamic loads generated by impact of structural vibration characteristics since there are many factors, each affecting different parameters affect the vibration characteristics of the structure is not the same cause.

\section{Analysis of dynamic characteristics of prestressed truss}

Computing model and calculation assumes When conducting evacuation prestressed grid computing power, take the following simplified model and assumptions

A. grid structure into a plurality of discrete lumped mass elastic system, grid nodes are hinged node space, each node has three degrees of freedom

B. belong to a small range of structural vibration , that structure belongs to a small deformation areas

C. structural damping is very small, which can affect the structure ignored coupled between the various modes

D. rod only bear axial force, the cable unit only tensile stress

E. structure to meet the conditions of displacement and strain conditions

\section{Grid structure vibration equation}

According to D'Alembert principle , acting on particle system active force and constraint forces and inertia force vector is zero, when the effects of structural damping is ignored, but this time the external force is zero , then the grid structure represented by the matrix free vibration equation can be expressed as[3]

$[M]\{\ddot{\delta}\}+[K]\{\delta\}=0$

$[M]$--Mass matrix, is a matrix in which the grid nodes; 
$[K]$-- The overall stiffness matrix

$\{\delta\}$-- Displacement array $\{\delta\}=\left\{\begin{array}{lllllllll}u_{1} & v_{1} & w_{1} & \cdots & u_{i} & v_{i} & w_{i} & \cdots & w_{n}\end{array}\right\}^{T}$;

$\{\ddot{\delta}\}$-- Acceleration Array $\{\ddot{\delta}\}=\left\{\begin{array}{lllllllll}\ddot{u}_{1} & \ddot{v}_{1} & \ddot{w}_{1} & \cdots & \ddot{u}_{i} & \ddot{v}_{i} & \ddot{w}_{i} & \cdots & \ddot{w}_{n}\end{array}\right\}^{T}$

Attributed to $\left|[K]-\omega^{2}[M]\right|=0$

$$
\{\omega\}=\left[\begin{array}{llll}
w_{1} & w_{2} & \cdots & w_{m}
\end{array}\right]^{T}
$$

In this paper, we use the block Lanczos method to solve the vibration frequency structure.

\section{Parametric analysis of prestressed composite truss vibration characteristics}

\section{Examples}

In this paper, taking the time to type diagonal square pyramid truss bottom chord as the basic model pit tendon disposition.The structure modal analysis using finite element software ANSYS. Grid infrastructure to take the winding $11 \times 11$ grid $(46.67 \mathrm{~m} \times 46.67 \mathrm{~m})$, grid basic parameters: truss top chord $\mathrm{lx}=\mathrm{ly}=3 \mathrm{~m}$, the distance between the upper and lower chords of $\mathrm{Z}=3 \mathrm{~m}$, prestressed cable strut $\mathrm{h}=1 \mathrm{~m}$, pretensioned $\mathrm{P}=100 \mathrm{KN}$.

Factors evacuated the vibration characteristics of prestressed truss

To evacuate diagonal square pyramid truss bottom chord Pit Tendon Disposition for example, adjusting the various parameters investigated various parameters on the natural frequencies of the grid[4].

Impact on the structure of the different values of prestressed.

Prestressed truss structure, cable tensioning process will at certain stiffness in a certain margin to increase the stiffness of the structure. Cable stiffness and prestress exerted on the cable -related, according to the semi- parallel wire cable tension range, were taken prestressed value $\mathrm{P}=0 \mathrm{KN}$, $100 \mathrm{KN}, 200 \mathrm{KN}, 400 \mathrm{KN}, 600 \mathrm{KN}$ for analysis, view different prestressing degree By taking the time to value the role of prestressed grid of diagonal square pyramid vibration frequency .

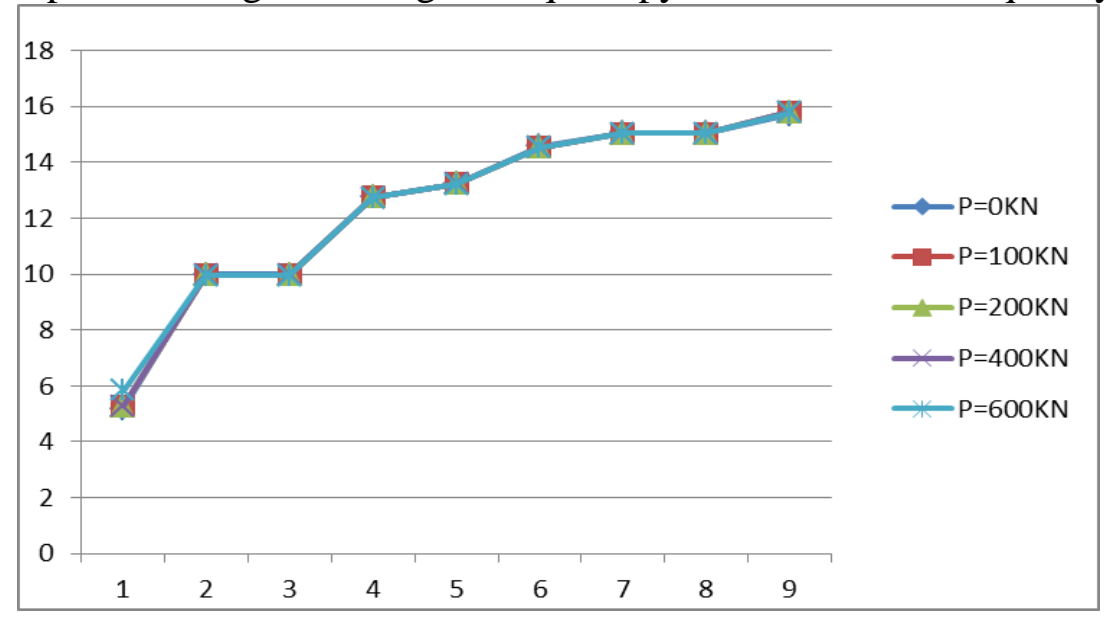

Under the effect of different values of prestressed truss bottom chord Pit evacuated tendon disposition frequency plot.

Shown in Figure 1-1 by can be seen taking the time to apply different degrees of prestressed diagonal square pyramid grid model, the grid value changed little since the vibration frequency, the conclusion in line with the situation . In taking the time to diagonal square pyramid grid model conclusion, we can see the same value the role of prestressed structural natural frequency with increasing order increases[5].

\section{Different heights natural frequency grid}

Rack height affects the appearance of the nature of the grid architecture. Grid height is too high, affecting the appearance, the lower the value would cause insecurity visual. Meanwhile, a different 
grid height can directly affect the stiffness of the structure, changing the distribution of member forces, displacement size value and the structure of the natural period so performance. The natural cycle will affect the value of the seismic response spectra and seismic internal force distribution. This section of different grid heights natural cycle analysis, the following table shows the changes in the structure of the natural frequencies of the trend with grid height values change, which highly values the grid were taken basic value $\mathrm{z}=3 \mathrm{~m}$, and $\mathrm{z}=2.5 \mathrm{~m}, \mathrm{z}=3.5 \mathrm{~m}, \mathrm{z}=4 \mathrm{~m}$.

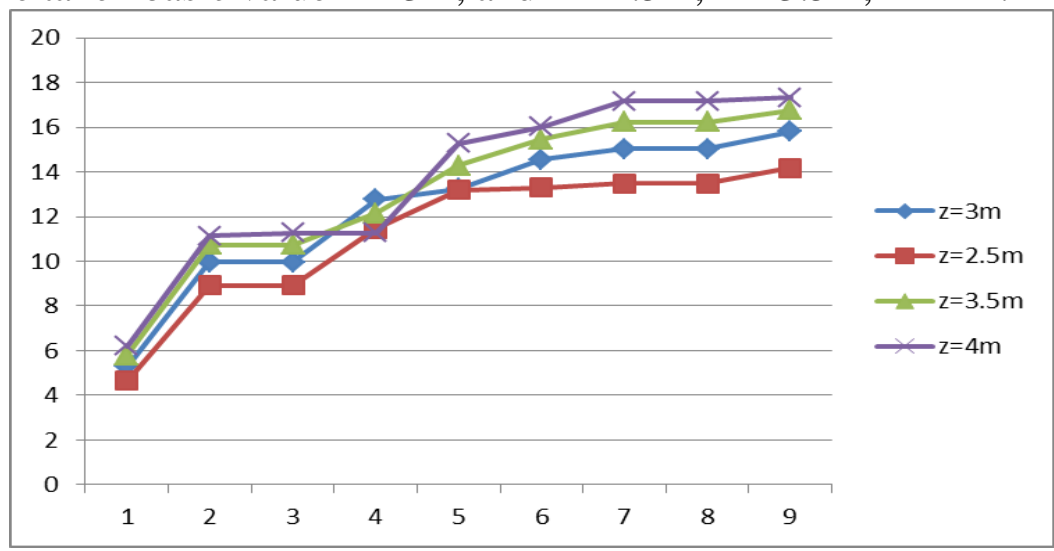

Different grid truss bottom chord height evacuated Pit Tendon Disposition frequency plot

As can be seen from the above Figure 1-2, the larger impact on the frequency grid height evacuated prestressed grid when the grid height $\mathrm{z}=2.5 \mathrm{~m}$, the grid of the lowest natural frequency, with the ever increasing height large grid of increasing frequency. That is, with increasing height grid, grid greater stiffness, and flexibility smaller.

Different mesh sizes vibration frequency

This study was evacuated to the grid, the mesh size increases, the lighting network structure, permeability is better, but the removing portion of the rod member, the mesh size is reduced too large, the safety of the structure . Mesh size decreases, the permeability is not enough, lighting rate has dropped, but the structure of the security increases. The following figure shows the trend of the value of the structure with the natural cycle of the mesh size, in which highly values the grid were taken basic values $\mathrm{lx}=\mathrm{ly}=3 \mathrm{~m}$, and $\mathrm{lx}=\mathrm{ly}=2.5 \mathrm{~m}, \mathrm{~lx}=\mathrm{ly}=3.5 \mathrm{~m}, \mathrm{~lx}=\mathrm{ly}=4 \mathrm{~m}$.

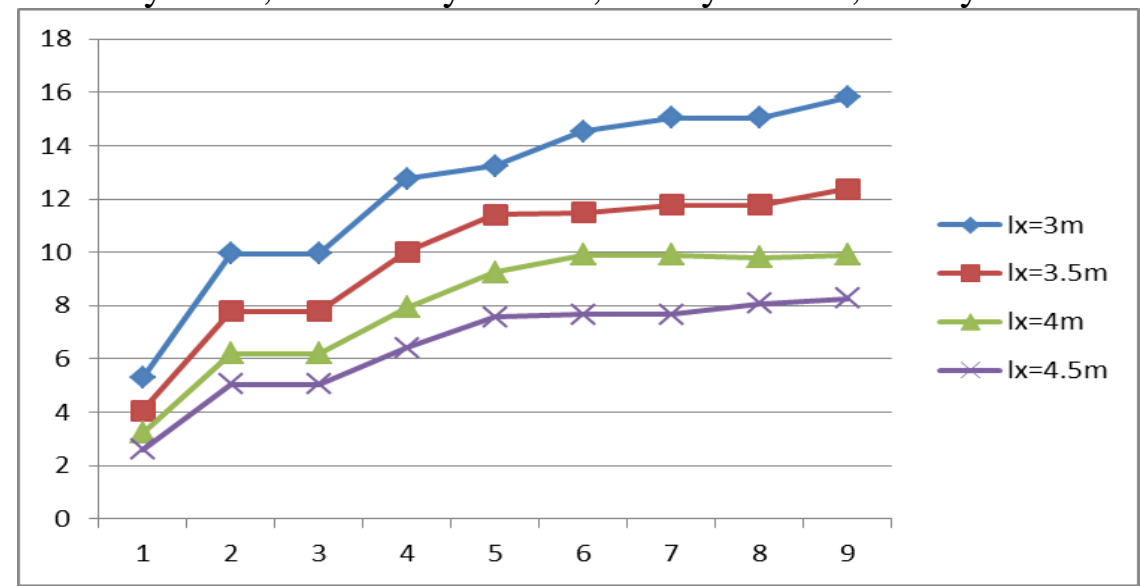

Different mesh sizes evacuated pit bottom chord truss tendon disposition frequency plot

From the above it can be seen in figure 1-3, the grid size change on the frequency value evacuated prestressed larger grid when the grid size is $\mathrm{lx}=\mathrm{ly}=3 \mathrm{~m}$, the grid frequency of the highest value, with a high degree of continuous increased frequency grid continues to decrease. That is, with increasing mesh sizes, the smaller grid stiffness, and greater flexibility.

Different pole heights prestressed cable vibration frequency

Brace for different lengths of prestressed structural vibration cycle analysis, the following figure shows the trend of structural vibration period with prestressed strut length value changes, which were taken strut highly value the basic values of $h=1 \mathrm{~m}$ and $\mathrm{h}=0.5 \mathrm{~m}, \mathrm{~h}=0.1 \mathrm{~m}, \mathrm{~h}=1.5 \mathrm{~m}$. When analyzing the $\mathrm{h}=0.1 \mathrm{~m}$ approximately equivalent to an internal tendon disposition form, that 
disguise internal research and external of cable of cable arrangements two types of self- oscillation cycle trends.

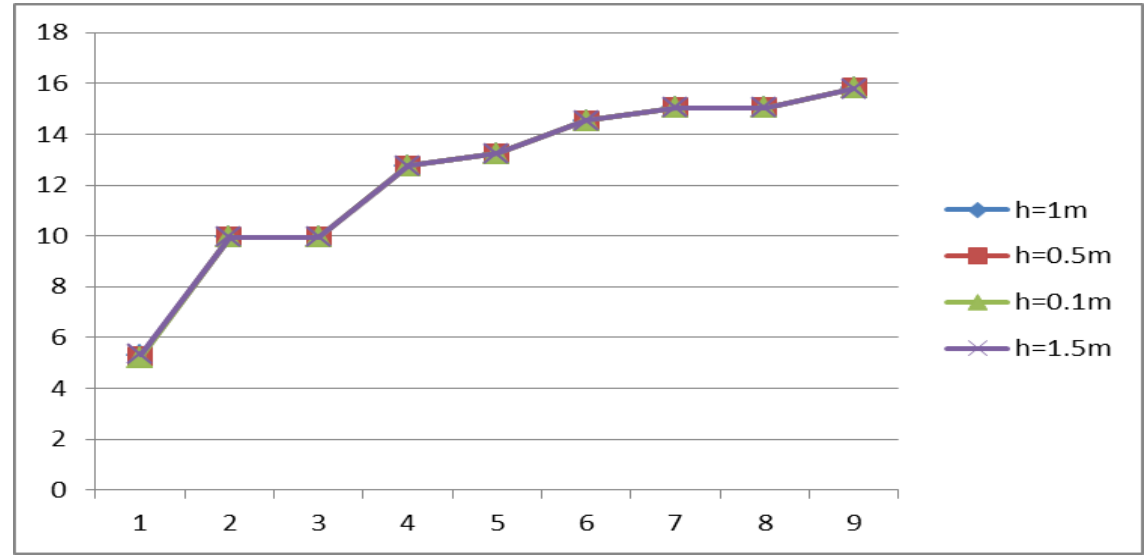

Different prestressed cable truss bottom chord brace height evacuated pit tendon disposition frequency plot

As can be seen by Figure 1-4, prestressed brace height grid and prestressed cable connection between the structure of the grid frequency changes little effect. It can basically come, whether it is inside or outside the gallery cable arrangements of cable, prestressed brace height variation of types of evacuation pyramidic prestressed diagonal grid frequency values are not affected.

\section{Conclusion}

Grid mesh size and height of the structure of the natural frequencies greater impact and influence of prestressed prestressed brace height and size is very small. Structure can be derived by calculating changes in the composition is a major factor affecting structural vibration characteristics. In engineering such a prestressed structure by adjusting the height of the grid, the grid size and site conditions, structural use, cost aspects to choose the best solution.

\section{References}

[1] Shen Yanzu, Chen Yangji, grid and lattice shell [M], Shanghai. Tongji University Press. 1997

[2] Chen Xinggang The bird's nest shaped space truss structure of the static and dynamic performance research Zhejiang: Zhejiang University, 2004

[3] Meng Wenqing, Zhang Chao, Mo Zongyun Cable and concrete plate is pre-stressed composite space truss natural vibration characteristic analysis [J]. Journal of Xiangtan university journal of natural science, 2010, 32 (1): 4 to 6

[4] C.Lanczos, An iteration method for the solution of the eigenvalne problem of linear differential and integral operators,J.Res.Nat.Bur.Standard,Sect.B45:225-280,1950

[5] Paige.C.C,The computation of eigenvalues and eigenvectors of very large sparse matrices[D], PH.D.thesis,Univ. of London,1971 